\title{
The Impact of Community Terrorism and Clashes on Quality of Care of Clients in HIV Program in Nigeria. (The Taraba Experience)
}

\author{
Article by Pharm Bruno A. Abebe, Pharm. Pinkai Aloysius, Pharm. Solomon Abe \\ B.Pharm Texila American University, Nigeria \\ Email: bruno.abebe@gmail.com
}

\begin{abstract}
One of the major challenges mitigating against the success of the HIV program in Nigeria, particularly in Taraba state, the state under study, was the incidence of community terrorism and clashes between the TIV farmers and Fulani herdsman that happened across certain communities where healthcare facilities were located that offered HIV program. This article will analyze the HIV program in Taraba state and how community terrorism and clashes has contributed to poor quality of care received by HIV patients and led to the dearth of healthcare workers, such as doctors, Pharmacists, nurses, laboratory scientists, record staffs etc and consequently contributed to the high prevalence of HIV in the state.
\end{abstract}

\section{Introduction}

The HIV program in Nigeria has being in operation for over ten years now. In a new national survey conducted by the federal government for the 2012 National HIV/AIDS and Reproductive Health Survey-Plus (NARHS Plus), Nigeria's HIV/AIDS prevalence rate is now 3.4 per cent. This is compared with 3.6 per cent in 2007, in some states the program have been quite successful, with a reduction in the HIV prevalence, while others have witnessed increase in prevalence. The state under study, Taraba state had a prevalence of 5.8 in 2010, the 2012 National HIV/AIDS and Reproductive Health Survey-Plus (NARHUS Plus) showed that HIV prevalence in Taraba has risen to 10.5. The increase in HIV prevalence in Taraba state has being greatly affected by the continuous occurrence of community terrorism and clashes between certain groups of tribes and people of different religions and has also contributed to the dearth of healthcare workers in most of the healthcare facilities. Over the years, a number of healthcare workers in these facilities where crisis took place have moved or retired and none have being replaced, this has affected the ability of healthcare workers to offer quality services to HIV clients. More especially the outbreak of community clashes in areas where hospitals and healthcare facilities are located have greatly affected access by patients to continue their treatment and care. The facility adversely affected is General Hospital Wukari, this community crisis occurred over a period of 2 years between 2013 and 2015.

\section{Materials and Method}

An exercise was carried out at General hospital Wukari, one of the major healthcare facility offering HIV treatment and care in Taraba state through a folder audit. I personally participated in auditing about 1,122 folders of clients on treatment and prophylaxis, out of over 15,000 clients that have being enrolled over a period of 9 years. The exercise involved screening patients' folders to ensure the following patient management and monitoring tools (PMM) are available; (i) initial clinical evaluation forms, (ii) adherence strategy work plan, (ii) medication adherence assessment form, (iv) laboratory request form showing baseline investigations, (v) ART care card, (vi) referral forms showing intra or inter referral linkage etc. These forms were screened and analyzed and the following data were extracted.

1. Patient Unique ID.

2. Patient Hospital number.

3. Age $(<1,>1-5,>15,>6-14)$.

4. Sex (Male and Female). 
South American Journal of Public Health

Special Edition May 2016

5. Date of enrollment.

6. Current CD4 count (value, Date, CD4 count in the last six month).

7. Current HAART Status

a) Initiated on HAART $(\mathrm{Y} / \mathrm{N})$

b) Date

c) Eligibility criteria used.

d) ARV regimen.

e) Last Pharmacy pickup.

f) Any Drug pick-up in the last three month $(\mathrm{Y} / \mathrm{N})$

8. Date of next appointment

9. Outcome of folder audit

a) Current on care

b) Current on HAART

c) Dead

d) Due for CD4 catch-up

e) Eligible based on CD4 count.

f) Lost to follow up

g) Transfer out.

\section{Results}

A total of one thousand one hundred and twenty-two $(1,122)$ folders were audited and the following information and data were extracted.

\begin{tabular}{|c|c|c|c|c|c|c|}
\hline $\mathrm{S} / \mathrm{N}$ & PARAMETER & TOTAL & MALE & $\%$ MALE & FEMALE & $\begin{array}{l}\% \\
\text { FEMALE }\end{array}$ \\
\hline 1 & \multicolumn{6}{|l|}{ AGE } \\
\hline & $<1 \mathrm{YR}$ & 7 & 3 & $42.86 \%$ & 4 & $57.14 \%$ \\
\hline & $>1-5 Y R$ & 8 & 5 & $62.50 \%$ & 3 & $37.50 \%$ \\
\hline & $>15 Y R$ & 1101 & 375 & $34.06 \%$ & 726 & $65.94 \%$ \\
\hline & $>6-14 \mathrm{YR}$ & 8 & $25 \%$ & $33.33 \%$ & 6 & $75.00 \%$ \\
\hline \multirow[t]{9}{*}{2} & \multicolumn{6}{|c|}{ Date of Enrollment of clients. } \\
\hline & 2006 & 2 & 0 & $0.00 \%$ & 2 & $100.00 \%$ \\
\hline & 2007 & 108 & 46 & $42.59 \%$ & 62 & $57.41 \%$ \\
\hline & 2008 & 256 & 100 & $39.06 \%$ & 156 & $60.94 \%$ \\
\hline & 2009 & 260 & 75 & $28.85 \%$ & 185 & $71.15 \%$ \\
\hline & 2010 & 295 & 105 & $35.59 \%$ & 190 & $64.41 \%$ \\
\hline & 2011 & 54 & 20 & $37.04 \%$ & 34 & $62.96 \%$ \\
\hline & 2012 & 86 & 20 & $32.26 \%$ & 66 & $76.74 \%$ \\
\hline & 2014 & 32 & 12 & $37.50 \%$ & 20 & $62.50 \%$ \\
\hline \multirow[t]{6}{*}{3} & \multicolumn{6}{|c|}{ CD4 count done in the last six months, (March-August 2015) } \\
\hline & Yes & 7 & 1 & $14.29 \%$ & 6 & $85.71 \%$ \\
\hline & No & 1114 & 384 & $34.47 \%$ & 730 & $65.53 \%$ \\
\hline & \multicolumn{6}{|c|}{$\begin{array}{l}\text { Percentage number of audited clients' folder that had CD } 4 \text { count done in the last six } \\
\text { months = } 0.62 \% \\
\text { Percentage number of audited clients' folders that had no CD4 count done in the last } \\
\text { six months }=99.38 \%\end{array}$} \\
\hline & CD4 done in 2015 & 17 & 5 & $29.41 \%$ & 12 & $70.59 \%$ \\
\hline & CD4 done in 2013 & 64 & 20 & $31.25 \%$ & 44 & $68.75 \%$ \\
\hline 4 & \multicolumn{6}{|l|}{ Initiated on HAART } \\
\hline & Yes & 706 & 225 & $31.87 \%$ & 481 & $68.13 \%$ \\
\hline & No & 408 & 159 & $38.97 \%$ & 249 & $61.03 \%$ \\
\hline
\end{tabular}


South American Journal of Public Health

Special Edition May 2016

\begin{tabular}{|c|c|c|c|c|c|c|}
\hline & \multicolumn{6}{|c|}{ Percentage number of audited clients' folders not on HAART $=39.62 \%$} \\
\hline \multirow[t]{7}{*}{5} & \multicolumn{6}{|c|}{ ARV Regimen } \\
\hline & First Line & 728 & 229 & $31.46 \%$ & 499 & $68.54 \%$ \\
\hline & Second Line & 3 & 1 & $33.33 \%$ & 2 & $66.67 \%$ \\
\hline & \multicolumn{3}{|l|}{6} & \multicolumn{3}{|c|}{ Drug Pick up in the last 3 months } \\
\hline & Yes & 199 & 62 & $31.16 \%$ & 137 & $86.84 \%$ \\
\hline & No & 920 & 321 & & 599 & \\
\hline & \multicolumn{6}{|c|}{$\begin{array}{l}\text { Percentage number of audited clients' folders that picked up drugs at least once in the } \\
\text { last three months }=17.78 \% \\
\text { Percentage number of audited clients folders that failed to pick up drugs at least once } \\
\text { in the last three months }=82.22 \%\end{array}$} \\
\hline 7 & Current on care & 1 & 1 & $100.00 \%$ & 0 & $0.00 \%$ \\
\hline & Current on HAART & 8 & 2 & $25.00 \%$ & 6 & $75.00 \%$ \\
\hline & $\begin{array}{l}\text { Clients due for CD4 } \\
\text { count test }\end{array}$ & 178 & 52 & $29.21 \%$ & 126 & $70.79 \%$ \\
\hline & \multicolumn{6}{|c|}{ Last CD4 count value, for clients due for CD4 count test } \\
\hline & $\begin{array}{l}1000-500 \text { CD4 } \\
\text { count }\end{array}$ & 19 & 4 & $21.05 \%$ & 15 & $78.95 \%$ \\
\hline & $499-400$ CD4 count & 15 & 6 & $40.00 \%$ & 9 & $60.00 \%$ \\
\hline & $399-300$ CD4 count & 18 & 3 & $16.67 \%$ & 15 & $83.33 \%$ \\
\hline & $299-200$ CD4 count & 41 & 11 & $26.83 \%$ & 30 & $73.17 \%$ \\
\hline & $199-100$ CD4 count & 53 & 16 & $30.19 \%$ & 37 & $69.81 \%$ \\
\hline & $99-1$ CD4 count & 27 & 6 & $22.22 \%$ & 21 & $77.78 \%$ \\
\hline & \multicolumn{6}{|c|}{$\begin{array}{l}\text { Percentage number of audited clients' folders retained on treatment and care }= \\
21.03 \% \\
\text { Percentage number of audited clients' folders lost to follow up }=78.97 \%\end{array}$} \\
\hline 8 & Lost to follow up & 886 & 315 & $35.55 \%$ & 571 & $64.45 \%$ \\
\hline & \multicolumn{6}{|c|}{ Lost to follow up (Distribution by year) } \\
\hline & 2007 & 65 & 27 & $41.54 \%$ & 38 & $58.46 \%$ \\
\hline & 2008 & 199 & 82 & $41.21 \%$ & 117 & $58.79 \%$ \\
\hline & 2009 & 194 & 62 & $31.96 \%$ & 132 & $68.04 \%$ \\
\hline & 2010 & 247 & 91 & $36.84 \%$ & 156 & $63.16 \%$ \\
\hline & 2011 & 46 & 20 & $43.48 \%$ & 26 & $56.52 \%$ \\
\hline & 2012 & 69 & 14 & $20.29 \%$ & 55 & $79.71 \%$ \\
\hline & 2014 & 22 & 9 & $40.91 \%$ & 13 & $59.09 \%$ \\
\hline
\end{tabular}

\section{Charts Representations.}

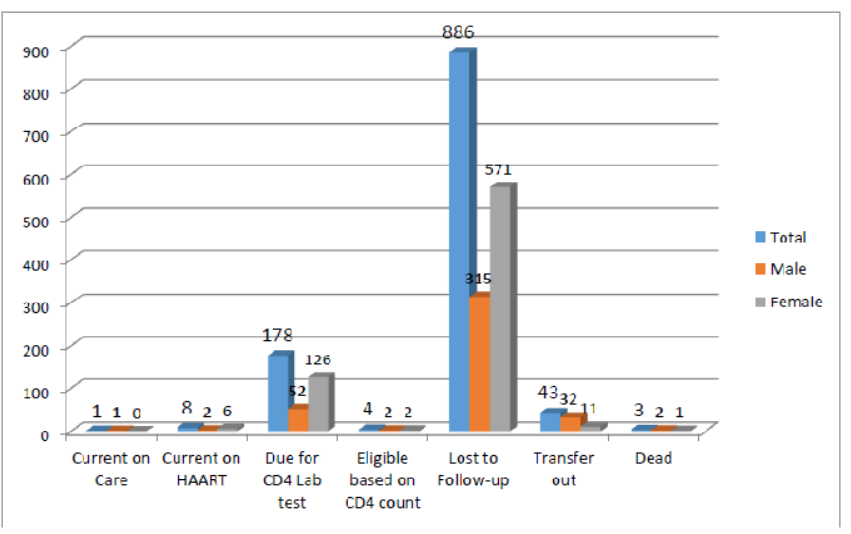

Figure 1 Outcome of Folder Audit. 
South American Journal of Public Health

Special Edition May 2016

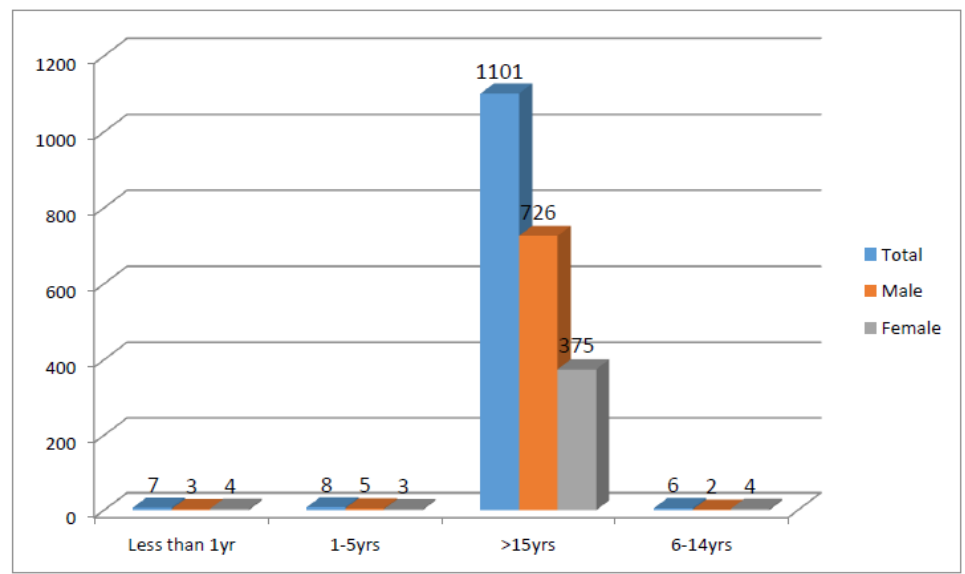

Figure 2 Age Distribution.

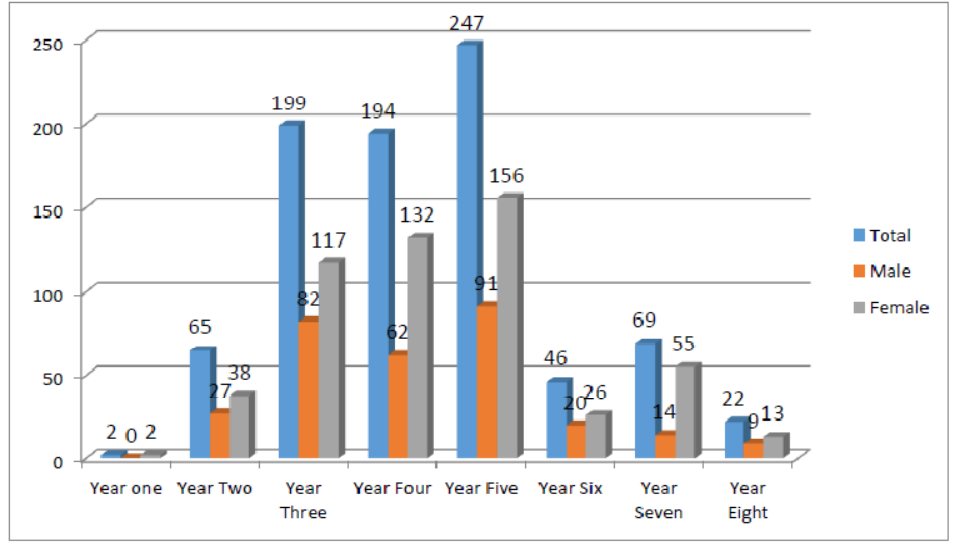

Figure 3 Loss to follow-up Distribution according to year of Enrollment.

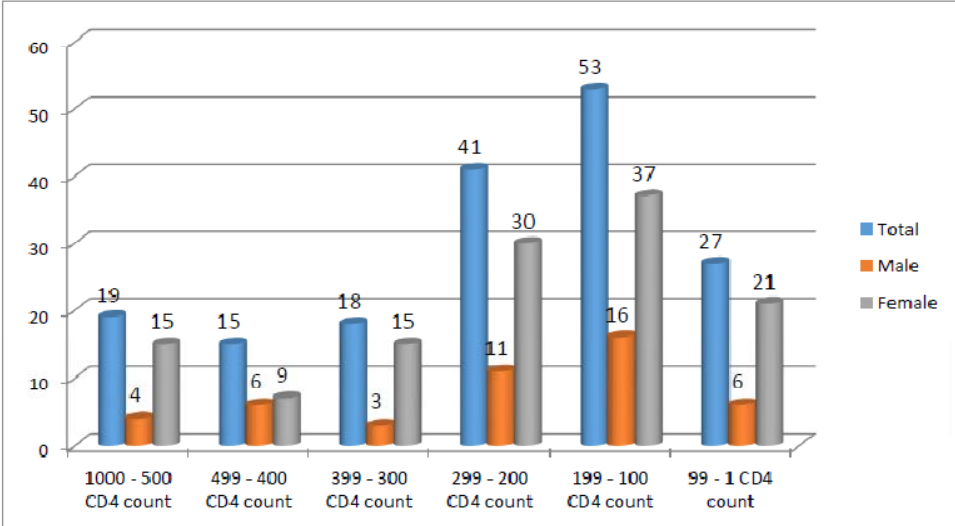

Figure 4 Last CD4 count done for clients versus number seem (Distribution class interval) 


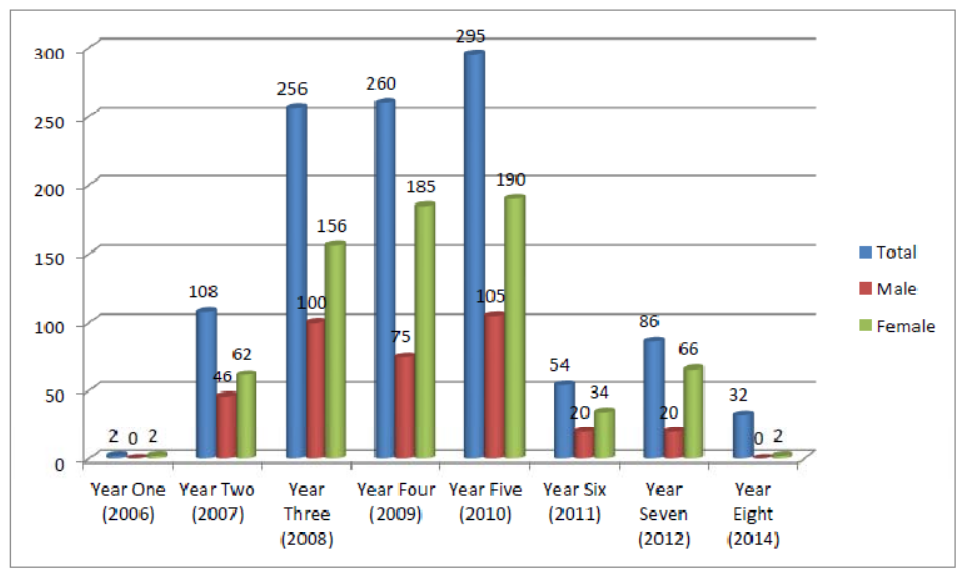

Figure 5 Date of Enrollment versus number seem, from Audited Clients folder

\section{Discussion}

Percentage number of audited clients' folder that had CD4 count done in the last six months (March-August 2015) was 0.62\%. Percentage number of audited clients' folders that had no CD4 count done in the last six months (March-August 2015) was 99.38\%. Percentage number of audited clients' folders initiated on HAART was $63.38 \%$. Percentage number of audited clients' folders not on HAART was $39.62 \%$. Percentage number of audited clients' folders retained on treatment and care was $21.03 \%$. Percentage number of audited clients' folders lost to follow up was $78.97 \%$.

From the chart presentations, comparing Figure 5 (chart on enrollment of clients) to Figure 3 (chart on lost to follow up) there seem to be a tremendous drop in number of clients retained on care and treatment in the facility. A huge number enrolled have being lost to follow up, some probably dead, some did self-transfer to other facilities without any official document, and others enrolled in other facilities as new clients. The analyzed data showing very low CD4 count of $0.62 \%$ for 236 (21.03\%) clients currently on treatment and care is proof of poor quality of care of clients. Clients on treatment and care are meant to be routinely monitored and screened and sent for CD4 test and other laboratory investigations every six months, the low percentage of clients having current CD4 count results is proof of this.

The retention of clients on treatment and care was greatly affected during the community crisis that affected General hospital Wukari, the facility under study, where clients' folders were assessed. Over the years the number and quality of healthcare workers have also depreciated. The quality of adherence counseling, which is the bedrock of antiretroviral therapy (ART) have suffered tremendously. Trained and specialized healthcare workers are no longer working at this facility; the ones present are poorly motivated.

There is therefore an association between the outcome of patients care at GH Wukari and the crisis that affected access to healthcare at the facility.

\section{Acknowledgement}

My appreciation goes to all the staffs of General Hospital Wukari that assisted in the work and exercise involved during the folder audit.

\section{Literature cited}

Impact of terrorism on health and Hospital Anxiety Depression Scale Screening in medical students, Karachi, Pakistan

Pages with reference to book, From 275 To 280

Sara Nasim ( Institute of Physical and Medical Rehabilitation, Karachi. )

Mahjabeen Khan ( Department of Obstetrics and Gynecology and Clinical Trials Unit, Dow University of Health Sciences, Karachi. ) 
South American Journal of Public Health

Special Edition May 2016

Sina Aziz ( Department of Paediatrics, Abbasi Shaheed Hospital, Karachi Medical and Dental University, Karachi. )

\section{References}

[1.] Dolberg OT, Barkai G, Leor A, Rapoport H, Bloch M, Schreiber S. Injured civilian survivors of suicide bomb attacks: from partial PTSD to recovery or to traumatisation. Where is the turning point? World J Biol Psychiatry 2010; 11: 344-51.

[2.] Gillespie K, Duffy M, Hackmann A, Clark DM. Community based cognitive therapy in the treatment of posttraumatic stress disorder following the Omagh bomb. Behav Res Ther 2002; 40: 34557.

[3.] Husain N, Creed F, Tomenson B. Depression and social stress in Pakistan. Psychol Med 2000; 30: 395-402.

[4.] Innovations in Civic Participants. (Online) (Cited 2011 March 30) . Avaiable from URL: www.icicp.org/ht/d/sp/d/sp/a/GetDocumentAction/i/4801.

[5.] Mumford DB, Tareen IA, Bajwa MA, Bhatti MR, Karim R.The translation and evaluation of an Urdu version of the Hospital Anxiety and Depression Scale. Acta Psychiatr Scand 1991; 83: 81-5. [6.] (Online) (Cited 2011 March 22). Available from URL: http://enwikipedia.org/wiki/list_of_terrorist_incidents_in_Pakistan_since_2001. [link not found] [7.] Reference for factor loading cut-off. (Online) (Cited 2013 Sep 2). Available from URL: http://spssx-discussion.1045642.n5.nabble.com/Reference-for-factor-loading-cut-off-td1087452.html. [8.] Schindel-Allon I, Aderka IM, Shahar G, Stein M, Gilboa-Schechtman E. Longitudinal associations between post-traumatic distress and depressive symptoms following a traumatic event: a test of three models. Psychol Med 2010; 40: 1669-78.

[9.] What Is Terrorism? (Online) (Cited 2013 Sep 2). Available from URL:

http://www.journalofamericanhistory.org/teaching/2011_06/sources/day1ex3_fbi_definitions.htm [10.] Yehuda R, Hyman SE. The impact of terrorism on brain and behavior: what we know and what we need to know Neuropsychopharmacology 2005; 30: 1773-80. 